\title{
O BRINCAR COMO PROPOSTA DA EDUCAÇÃO INFANTIL
}

\author{
Patrícia Fracetto ${ }^{1}$ \\ Gabriela Guarnieri de Campos Tebet ${ }^{2}$
}

\section{Introdução}

O presente artigo tem como objetivo analisar o brincar enquanto proposta na Educação Infantil, à luz de uma experiência propiciada pela disciplina: Estágio Supervisionado III Educação Infantil - EP 912 C, da Faculdade de Educação (FE) - UNICAMP, ministrada pela professora Gabriela Guarnieri de Campos Tebet, no primeiro semestre de 2015. Tal estudo visa elaborar algumas análises a respeito da importância do brincar na Educação Infantil, considerando o desenvolvimento das crianças além da esfera cognitiva e assinalando a infância enquanto momento de construção de culturas infantis.

Desta forma, este artigo pretende descrever a intervenção realizada no estágio e também considerar algumas abordagens teóricas que discorrem sobre o papel do brincar no desenvolvimento infantil. A seguir, será construída uma breve contextualização do estágio e de suas propostas, bem como a descrição da intervenção realizada juntamente a duas crianças da Educação Infantil.

\section{Propostas do estágio supervisionado e descrição da intervenção}

Durante as atividades do estágio em Educação Infantil, a professora Gabriela Tebet ressaltou aos estagiários que mantivessem um olhar atento nas diversas experiências no campo. A ideia de intervenção foi proposta pela docente com o intuito de que os estudantes compreendessem o processo pedagógico enquanto algo intencional, oriundo de experiências suscitadas pelo cotidiano, no que se refere à construção das aprendizagens que podem ser propiciadas pela Educação Infantil, planejadas através de ações que procurem desenvolver nas crianças determinadas construções psíquicas, sociais e afetivas, sem deixar de valorizar as várias aprendizagens que ocorrem enquanto o professor não percebe.

Portanto, a partir dessa vivência na Educação Infantil e das discussões sobre o estágio, foram efetivadas algumas elaborações sobre o papel do(a) educador(a) nas mediações e intervenções, especificamente na relação entre a criança e o brincar. Essas questões foram suscitadas a partir de uma experiência na qual, uma criança aparentemente com mais dificuldades para se relacionar com as outras durante as brincadeiras, passou a brincar e a explorar aquele momento em específico, devido a uma situação de intervenção, situação esta que será descrita a seguir.

No terceiro dia de estágio na Creche da Área da Saúde (CAS - UNICAMP), quando a estagiária estava acompanhando as crianças durante suas atividades e brincadeiras, a mesma soube que duas meninas, as mais novas do grupo que acompanhava, tinham algumas dificuldades relacionadas à interação com as outras crianças de sua idade. No mesmo dia, quando as outras crianças já estavam brincando no parque, as duas crianças continuaram quietas e sem interagir, ficando sempre próximas da estagiária e de outra profissional da escola.

Por acreditar na importância das interações, a estagiária começou a incentivar as crianças a brincar no parque, sentou-se com elas e começou a brincar com os materiais dispostos na

\footnotetext{
${ }^{1}$ Universidade Estadual de Campinas.

${ }^{2}$ Universidade Estadual de Campinas.
} 
areia. Quando as duas meninas perceberam, estavam sentadas no parque, interagindo uma com a outra, com os brinquedos, com a areia e demais elementos.

Abaixo, está a fotografia que fora registrada durante intervenção:

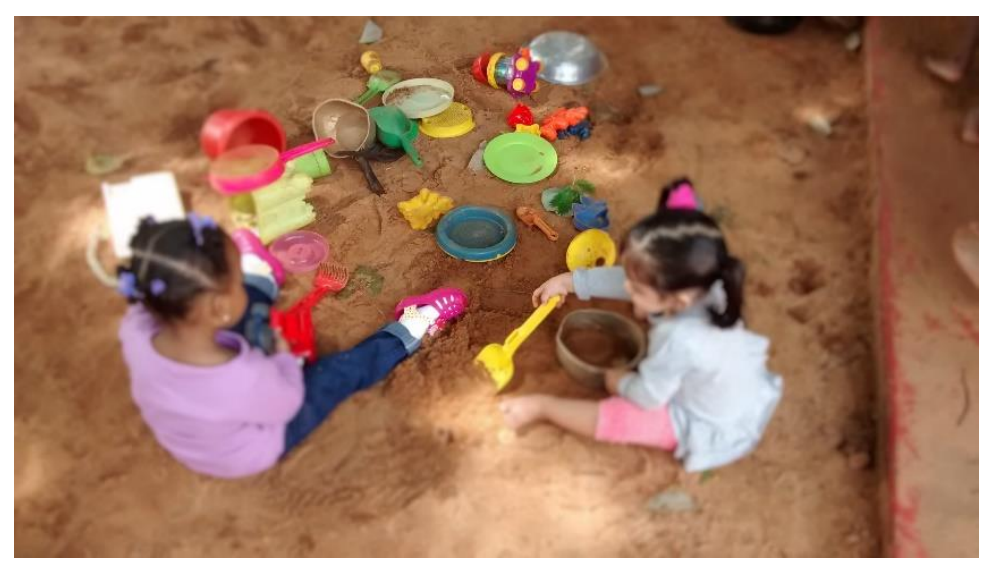

Fotografia da intervenção, registrada pela estagiária Patrícia Fracetto, no dia 20/03/2015.

Esta intervenção contribuiu, de alguma forma, para a inserção das duas crianças nas brincadeiras. Portanto, como apontam as Diretrizes Curriculares Nacionais para a Educação Infantil (2010), Villela \& Archangelo (2015), Corsaro (2002) e Vygotsky (1998, 2005), o brincar é essencial para o desenvolvimento infantil, por propiciar diversas aprendizagens, bem como representações sobre o mundo e seus diversos elementos, por isso esta situação em especial foi escolhida para ser analisada. Assim, a seguir, serão brevemente discutidas as contribuições teóricas em destaque.

\section{Referencial teórico da temática explorada}

As Diretrizes Curriculares Nacionais para a Educação Infantil (2010), assumem a ideia de que a proposta pedagógica para esta etapa da Educação Básica Brasileira deve ser desenvolvida tendo como eixos norteadores as interações e a brincadeira (p. 25). A partir desta legislação, é possível perceber que o brincar além de ser um direito da criança, também é, ou deveria ser, um dever dos órgãos responsáveis por sua execução.

O brincar, segundo Villela \& Archangelo (2015), pode ser assinalado como uma atividade realizada pelas crianças que expressa interpretações e reinterpretações das relações presentes no mundo. Assim, de forma breve, os autores destacam que:

Ao brincar, a criança não está no mundo adulto, mas com ele se relaciona a partir de um vértice original, exclusivamente criado por ela e para ela, e de onde ela avista também seu próprio mundo, comunicando-se com ele e transformando-o. É nesse espaço que ela experimenta criar outro mundo, no qual o sofrimento, a coerência, a preocupação com os outros podem ser experimentados, destruídos, recriados, sem que consequências do mundo exterior incidam sobre seu mundo interior. (VILLELA \& ARCHANGELO, 2015, p. 33 - 34.)

Corsaro (2002), apresenta uma abordagem interpretativa da socialização e pondera sobre estes processos na escola. Sobre isso, é necessário pontuar que existe uma relação fundamental que é concretizada pelas crianças com a natureza e a sociedade, de forma que todos os seres humanos efetivam a própria sociedade e a informação de alguma forma. $\mathrm{O}$ autor também 
denomina como "culturas infantis" os processos relacionados ao brincar e suas criações e recriações, enquanto parte de um processo de socialização que é importante para o desenvolvimento da criança.

O último aspecto teórico a ser abordado está relacionado com as essenciais noções de aprendizado que o brinquedo possibilita para a criança. Para Vygotsky (1998, 2005), a função simbólica da imaginação é o momento mais puro da representação do pensamento, devendo ser trabalhado através da linguagem e de atividades que possibilitem pensamentos elaborados através da internalização dos objetos culturais.

Levando em consideração as contribuições dos autores aqui expostos, é preciso pontuar a brincadeira como a mobilização de um movimento forte de união das crianças. Desta forma, falar sobre as culturas infantis requer estudá-las à luz das apropriações das diversas relações, a partir das criações e recriações que podem ser internalizadas com os diversos estímulos, tanto a partir do contato com a cultura, quanto a partir do contato das crianças com seus pares e adultos.

Vale lembrar que, as ações realizadas na intervenção, foram mediações estabelecidas a partir de uma necessidade vislumbrada no cotidiano. Faz-se necessário citar Vygotsky (1998, 2005) novamente, pois em um contexto educacional, mediar situações de aprendizagens implica em "fazer junto com a criança", e "não pela criança". Mediar indica, então, a prática de um suporte, para que, a partir das intervenções, a criança consiga, autonomamente, construir relações cooperativas tanto intelectuais quanto afetivas com as descobertas, referentes às aprendizagens e à leitura de mundo.

A mediação possui elementos concretos e também afetivos que fazem com que esse seja um processo dinâmico, definindo, assim, o modo pelo qual o sujeito estará adaptado ao meio. Vygotsky (1998, 2005) assinala que o aprendizado se dá através de sucessivas interlocuções entre o conhecimento já efetivado e aquele que, com ajuda, poderá ser internalizado. Então, a zona de desenvolvimento proximal seria a diferença entre o que a criança já faz autonomamente - nível de desenvolvimento real - e o que ainda realiza com auxílio do outro - nível de desenvolvimento potencial. O que no caso da intervenção, pode ser explicitado pelo suporte realizado através da mediação da estagiária, pois a capacidade de se inserir autonomamente nas brincadeiras e relações é construída nas ações contínuas do cotidiano.

Como o conceito de zona de desenvolvimento proximal já fora explanado anteriormente, o que fica relevante a partir da descrição e da reinterpretação gerada a partir da escrita da situação de intervenção, é que as duas meninas podem ter construído, em suas apropriações, ideias básicas relacionadas à socialização nas brincadeiras da creche. Para que tais apropriações possam fazer parte de suas aprendizagens autônomas, espera-se que outras mediações sejam realizadas, de forma a sustentar a intervenção anterior e auxiliar as crianças em seu desenvolvimento integral.

\section{Considerações finais}

Não pretendendo esgotar todas as reflexões deste artigo, é válido lembrar que este trabalho teve como finalidade o estudo breve de uma ação que provocou, em determinado momento, uma alteração nas formas de viver as brincadeiras no parque, de duas crianças da Creche da Área da Saúde (CAS), da UNICAMP. Foi necessário utilizar alguns apoios teóricos para amparar a fundamentação da intervenção, que foi efetuada em um momento significativo no estágio supervisionado em Educação Infantil. 


\section{Referências}

BRASIL. Diretrizes curriculares nacionais para a Educação Infantil. Brasília - Ministério da Educação, 2010. Disponível em: <http://portal.mec.gov.br/index.php?option=com_docman\&task=doc_download\&gid=9769\& Itemid.> Acesso em: 20/06/2016.

CORSARO, W. A. A reprodução interpretativa no brincar ao "faz-de-conta" das crianças. Educação, Sociedade e Cultura: Revista da Associação de Sociologia e Antropologia da Educação, Porto, v. 17, p. 113-134, 2002.

VILLELA, F. C. B.; ARCHANGELO, A. O brincar, o pensar e o aprender. In: . Livro III: A escola significativa e o aluno diante da atividade. ed. 1, São Paulo: Edições Loyola, 2015. p. 25-40. (Coleção A escola significativa).

VYGOTSKY, L. S. A formação social da mente. São Paulo: Martins Fontes, 1998. . Pensamento e Linguagem. São Paulo: Martins Fontes, 2005.

\section{Sobre as autoras}

Patrícia Fracetto é graduanda do quinto ano em Pedagogia pela FE-UNICAMP. Já trabalhou por dois anos como estagiária remunerada pela Prefeitura de Americana - SP. Atualmente, é bolsista de Iniciação Científica da FAPESP - Fundação de Amparo à Pesquisa do Estado de São Paulo, com o projeto intitulado: Ensinando a pesquisar: os impactos afetivos de um Projeto de Ciências em alunos do Ensino Fundamental II, sob responsabilidade do Prof. Dr. Sérgio Antônio da Silva Leite.

E-mail: patricia_fracetto@yahoo.com.br.

Gabriela Guarnieri de Campos Tebet é docente do Departamento de Ciências Sociais na Educação (DECISE), da Faculdade de Educação (FE), da Universidade Estadual de Campinas - UNICAMP.

E-mail: souza.fgabriela@gmail.com. 